Estudios Constitucionales, Año 17, No 2, 2019, pp. 53-90

ISSN 07180195

Centro de Estudios Constitucionales de Chile Universidad de Talca

"Acción de tutela contra sentencias de tutela: Una manifestación de la constitucionalización del derecho jurisprudencial en Colombia"

John Fernando Restrepo Tamayo - Ricardo Vergara Cardona

\title{
ACCIÓN DE TUTELA CONTRA SENTENCIAS DE TUTELA: UNA MANIFESTACIÓN DE LA CONSTITUCIONALIZACIÓN DEL DERECHO JURISPRUDENCIAL EN COLOMBIA ${ }^{* * * *}$
}

\author{
Tutela ACTION AGAINST CUSTODY SENTENCES: A MANIFESTATION OF THE \\ CONSTITUTIONALIZATION OF JURISPRUDENTIAL LAW IN COLOMBIA
}

\author{
JOHN FERnANDO RESTREPO TAMAYO** \\ Universidad de Medellín (Colombia) \\ jfrestrepo@udem.edu.co \\ Ricardo Vergara CARdona*** \\ Universidad de Medellín (Colombia)
}

\begin{abstract}
RESUMEN: A partir de la Sentencia SU-627 de 2015, el precedente constitucional vigente con relación a la procedencia de la acción de tutela contra sentencias de tutela, permite la aplicación de dos doctrinas constitucionales que se refinan hermenéuticamente entre sí sin generar la existencia de una linea jurisprudencial caótica: (i) la regla general de improcedencia de la acción de tutela contra sentencias de tutela argumentada en instituciones como el derecho a la segunda instancia, la eventual revisión de las sentencias de tutela, la cosa juzgada constitucional y el cumplimiento inmediato de la sentencia de tutela; $y$, (ii) la procedencia excepcional de la acción de tutela contra sentencias de tutela cuando se presente una situación de fraude que configure el fenómeno de la cosa juzgada fraudulenta en aplicación del principio fraus omnia corrumpit (el fraude lo corrompe todo). Este precedente constitucional puede calificarse como una manifestación de la constitucionalización del derecho jurisprudencial en Colombia que se caracteriza por: (i) la reconfiguración del sistema de fuentes del derecho; (ii) la incorporación de nuevos métodos de interpretación y, (iii) la apertura a nuevas formas de litigio constitucional.
\end{abstract}

\footnotetext{
* Artículo recibido el 9 de mayo de 2019 y aprobado el miércoles 6 de noviembre de 2019.

** Este artículo es resultado del trabajo académico que se adelanta en la línea de investigación Estado, Democracia y Constitución del Grupo de Investigación en Conflicto y Paz de la Facultad de Ciencias Sociales y Humanas de la Universidad de Medellín (Colombia); y se deriva del proyecto de investigación titulado: La participación ciudadana en el proceso constituyente de 1991.

*** Abogado (Universidad de Antioquia). Politólogo (Universidad Nacional). Magíster en Filosofía (Universidad de Antioquia). Doctor en Derecho (Universidad de Medellín). Docente de tiempo completo y Decano de la Facultad de Ciencias Sociales y Humanas de la Universidad de Medellín.

**** Abogado con énfasis en Derecho Público (Universidad de Medellín). Especialista en Derecho Administrativo (Universidad de Medellín). Candidato a Magister en Derecho (Universidad de Medellín). Docente catedrático de la Facultad de Ciencias Sociales y Humanas de la Universidad de Medellín.
} 
ABSTRACT: As of SU-627 of 2015, the current constitutional precedent regarding the admissibility of the tutela action against custody sentences allows the application of two constitutional doctrines that are hermeneutically refined without generating the existence of a chaotic jurisprudential line: (i) the general rule of inadmissibility of the tutela action against judgments of guardianship argued in institutions such as the right to the second instance, the possible revision of the sentences of guardianship, constitutional res judicata and the immediate enforcement of the guardianship sentence; and, (ii) the exceptional origin of the tutela action against custody sentences when a situation of fraud is presented that configures the phenomenon of fraudulent res judicata in application of the principle fraus omnia corrumpit (fraud corrupts everything). This constitutional precedent can be described as a manifestation of the constitutionalization of jurisprudential law in Colombia that is characterized by: (i) the reconfiguration of the system of sources of law; (ii) the incorporation of new methods of interpretation; and, (iii) the opening to new forms of constitutional litigation.

PALABRAS CLAVE: Acción de tutela contra sentencias de tutela, cosa juzgada fraudulenta, justicia material, constitucionalización del derecho jurisprudencial, precedente constitucional.

KEY WORDS: Tutela action against custody sentences, fraudulent res judicata, material justice, constitutionalization of the jurisprudential law, constitutional precedent.

\section{INTRODUCCIÓN}

El presente trabajo tiene por objeto analizar el precedente constitucional vigente y aplicable con relación a la procedencia excepcional de la acción de tutela contra sentencias de tutela, de acuerdo con el desarrollo progresivo de la jurisprudencia de la Corte Constitucional colombiana.

Para cumplir esta finalidad es necesario tener presente los cambios constitucionales que generó la Constitución Política de 1991 al instaurar el paradigma del Estado constitucional y democrático de derecho, donde la Constitución deja de ser un simple pacto político y se convierte en una norma jurídica vinculante que determina el criterio de validez formal y material de todo el ordenamiento jurídico, razón por la cual cuenta con una garantía de defensa jurisdiccional por parte de la Corte Constitucional ${ }^{1}$ que debe asegurar su integridad y supremacía. La Constitución Política de 1991, consagra la acción de tutela como el instrumento procesal por excelencia para garantizar la salvaguarda y efectividad de los derechos fundamentales ${ }^{2}$, que resulten vulnerados o amenazados por la acción u omisión de cualquier autoridad pública y, excepcionalmente, por los particulares cuando están encargados de la prestación de un servicio público y

\footnotetext{
1 Artículo 241 de la Constitución Política de Colombia.

2 Nogueira (2013), Tomo 1, p. 19.
} 
su actuación afecta gravemente el interés colectivo o la persona que solicita el amparo constitucional se encuentra en un estado de indefensión o subordinación ${ }^{3}$.

La acción de tutela puede ser interpuesta por cualquier persona sin importar su edad, raza, condición económica, religiosa o sexual, para reclamar ante la autoridad judicial, por sí misma o por medio de un tercero, la defensa pronta y efectiva de sus derechos fundamentales, cuando resulte necesario para evitar un perjuicio irremediable o cuando no exista otro medio de defensa judicial eficiente para garantizar esta finalidad constitucional ${ }^{4}$.

La acción de tutela tiene un trámite preferente, sumario y, por regla general, carece de tecnicismos y formalismos ${ }^{5}$. La autoridad judicial debe resolverla dentro de los 10 días hábiles siguientes a su presentación y no puede proferir una sentencia inhibitoria, salvo que la acción de tutela sea improcedente ${ }^{6}$. En el trámite de la acción de tutela, la justicia constitucional realiza un control concreto de constitucionalidad resolviendo por regla general, con efectos inter partes, la controversia jurídica presentada, es decir, los efectos de la decisión judicial están circunscritos al caso en concreto ${ }^{7}$.

Sin embargo, la Corte Constitucional puede ampliar los efectos de las sentencias de revisión de tutela asignándoles un efecto inter pares o un efecto inter comunis. Los efectos inter pares son un dispositivo amplificador de la decisión al cual la Corte Constitucional acude cuando con relación a un problema jurídico determinado considera que existe una única respuesta válida de conformidad con las disposiciones constitucionales, la cual debe aplicarse a todos los casos similares sin excepción alguna. Por medio de los efectos inter comunis la Corte Constitucional ordena que los efectos de la sentencia de tutela se extiendan y apliquen a un grupo de personas que conforman una colectividad que tiene unas situaciones fácticas y jurídicas similares a las analizadas, sin importar si han presentado previamente una acción de tutela ${ }^{8}$.

\footnotetext{
3 Artículo 86 de la Constitución Política de Colombia; artículo 42 del Decreto No 2.591 de 1991; UsCangA y López (2011), pp. 350-358.

4 Botero (2006), pp. 10-11; Correa (2009), pp. 36-37; Carrera (2011), pp. 77-78.

5 Giacomette (2017), p. 411; Angarita (2017), p. 94.

6 Artículos 60 y 29 del Decreto No 2.591 de 1991.

7 Castaño (2010), p. 390; González (2014), p. 176.

8 Gonzalez (2014), pp. 178-180; Corte Constitucional de Colombia, Sentencia SU-037 de 2019.
} 
Si bien la acción de tutela promueve el acceso al servicio público de administración de justicia y la efectividad del derecho a la tutela judicial efectiva de los derechos fundamentales, la evolución de la teoría constitucional, los cambios sociales, económicos, políticos y jurídicos del país y el empoderamiento ciudadano de los derechos fundamentales, han generado que a la hora de tramitar y decidir este instrumento procesal constitucional se presenten deficiencias metodológicas, entendidas como problemas interpretativos para construir la teoría y decisión judicial del caso, que no pueden solucionarse conforme con las disposiciones constitucionales que regulan su consagración originaria y expresa en los artículos 86 y 241 \# 9 de la Carta Superior.

Es necesario que la Corte Constitucional por medio de su jurisprudencia cree remedios judiciales para contrarrestar estas deficiencias metodológicas con el objetivo de asegurar el fin constitucional de la acción de tutela: la protección judicial efectiva de los derechos fundamentales. Con tal finalidad, a partir de la Sentencia SU-627 de 2015, la Corte Constitucional colombiana fija las subreglas vigentes que permiten la procedencia excepcional de la acción de tutela contra sentencias de tutela. Sin embargo, la doctrina constitucional relacionada con la regla general de la improcedencia de la acción de tutela contra este tipo de sentencias no ha perdido vigencia en la jurisprudencia constitucional.

A partir de la Sentencia SU-627 de 2015, la Corte Constitucional realiza una reconceptualización doctrinaria de esta institución jurídica. Respetando la regla general de su improcedencia, generó un cambio jurisprudencial fuerte en el interior de la línea jurisprudencial existente y determinó un excepcionalísimo escenario constitucional ${ }^{9}$ en el cual sí es procedente la acción de tutela contra sentencias de tutela. En este caso, la excepción no solo confirma la regla sino que la redefine o refina hermenéuticamente. Con fundamento en pronunciamientos jurisprudenciales anteriores, específicamente las Sentencias T-218 de 2012, T-951 de 2013, T-272 de 2014 y T-373 de 2014, la Corte Constitucional pretende garantizar la tutela judicial efectiva de los derechos fundamentales, en especial del derecho fundamental al debido proceso ${ }^{10}$.

9 "Un escenario constitucional es el patrón fáctico en el que la Corte ha especificado, mediante subreglas, el significado concreto de un principio constitucional abstracto". "Es una zona de choque de intereses donde la Corte puede desplegar el análisis de la Constitución para encontrar balances que maximicen la protección de derechos en conflicto dentro de esa zona de choque". López (2006), pp. 148, 154.

10 Araújo (2015), pp. 572, 581. 
Para entender el cambio jurisprudencial generado por la Sentencia SU-627 de 2015, es pertinente recordar que el derecho jurisprudencial se desarrolla de manera lenta y progresiva. Para identificar las subreglas vigentes o las normas controlantes del caso es necesario realizar un análisis temporal y estructural de varias sentencias relacionadas entre sí, atendiendo al "principio de sistemacidad en la interpretación jurisprudencial”, que indica que un párrafo no puede ser interpretado adecuadamente aislado de la sentencia que lo contiene y, una sentencia no puede ser interpretada adecuadamente aislada de la línea jurisprudencial a la que pertenece ${ }^{11}$.

Para identificar el precedente constitucional vigente y aplicable con relación a la procedencia de la acción de tutela contra sentencias de tutela, es necesario dividir su estudio en dos momentos: (i) antes de la Sentencia SU-627 de 2015 y, (ii) a partir de la Sentencia SU-627 de 2015. Por esta razón, se presenta el siguiente gráfico que resume la línea jurisprudencial construida por la Corte Constitucional.

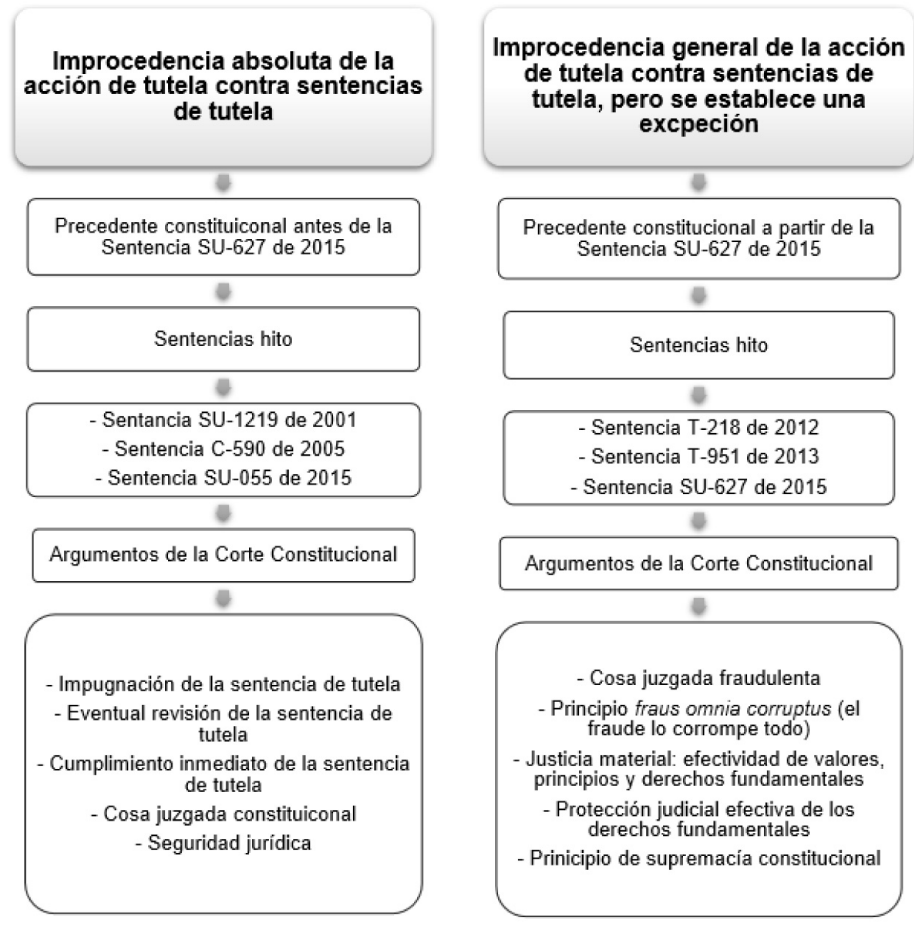

Fuente: elaboración propia

11 López (2006), pp. 139, 256. 
La acción de tutela contra sentencias de tutela es una nueva forma de litigio constitucional que tuvo su origen jurisprudencial en la necesidad imperiosa que tenía la Corte Constitucional de crear una técnica decisoria o remedio judicial que permitiera revisar y corregir los efectos patrimoniales y presupuestales que generaron varias sentencias de tutela que concedieron, por medios fraudulentos, reconocimientos pensionales a determinados docentes del país. Circunstancia que estaba generando un detrimento patrimonial al Estado y un grave problema jurídico al fondo que administraba estos recursos, debido a que, la negativa de autorizar el ingreso a nómina o de continuar pagando las mesadas pensionales generaron la presentación de numerosos incidentes de desacato sin que existiera un instrumento jurídico que permitiera oponerse porque estos fallos no habían sido seleccionados para su revisión por parte de la Corte Constitucional, adquiriendo el efecto de cosa juzgada constitucional. Actualmente, esta modalidad de procedencia excepcional de la acción de tutela continúa presentándose, por regla general, en materia pensional.

Este trabajo se desarrolla por medio de la metodología de investigación jurídica denominada análisis jurisprudencial constitucional o de construcción de líneas jurisprudenciales conformada por los siguientes dos pasos: (i) el análisis dinámico del precedente judicial que permite identificar las sentencias hito que contienen la retórica y el marco de análisis del tema concreto que se estudia y, (ii) el análisis estático del precedente judicial que permite interpretar e identificar su vigencia y aplicabilidad en cada escenario constitucional ${ }^{12}$.

Para cumplir con el objetivo propuesto, este trabajo se desarrolla en tres partes: (i) el precedente constitucional vigente y aplicable antes de la Sentencia SU-627 de 2015; (ii) el precedente constitucional vigente y aplicable a partir de la Sentencia SU-627 de 2015 y, (iii) la constitucionalización del derecho jurisprudencial en Colombia.

\section{EL PRECEDENTE CONSTITUCIONAL VIGENTE Y APLICABLE ANTES DE LA SENTENCIA SU-627 DE 2015}

A partir de la Sentencia SU-1219 de 2001, la Corte Constitucional estableció de manera consolidada y reiterada la doctrina constitucional de la improcedencia de la acción de tutela contra sentencias de tutela. Con fundamento en esta sen-

12 LÓpez (2006), pp. 139-264. 
tencia hito ${ }^{13}$, la Corte Constitucional construyó la línea jurisprudencial ${ }^{14}$ que le permitió responder el problema jurídico: ¿Puede interponerse una acción de tutela contra una sentencia de tutela alegando que se ha incurrido en un grave error judicial que vulnera derechos fundamentales?

Estas actuaciones judiciales vulneradoras de derechos fundamentales fueron desarrolladas por la Corte Constitucional mediante el concepto de "vías de hecho". Sin embargo, a partir de las Sentencias T-774 de 2004 y C-590 de 2005 esta expresión fue reemplazada por "causales específicas de tutela contra sentencias", término que abarca los conceptos de capricho y arbitrariedad judicial ${ }^{15}$.

De acuerdo con la Corte Constitucional no solo se trata de los casos en que el juez impone, de manera grosera y burda su voluntad sobre el ordenamiento (vía de hecho), sino que incluye aquellos casos en los que se aparta de los precedentes sin argumentar debidamente (capricho) y cuando su discrecionalidad interpretativa se desborda en perjuicio de los derechos fundamentales de los asociados (arbitrariedad) ${ }^{16}$.

La Corte Constitucional reconoce que la justicia constitucional no es infalible y que los jueces de tutela pueden cometer errores que lesionen derechos fundamentales. Sin embargo, los mecanismos jurídicos para solicitar la protección de estos derechos ante un error judicial son diferentes dependiendo de si son actuaciones realizadas por los jueces ordinarios o por los jueces de tutela ${ }^{17}$.

En el primer evento, además de existir los instrumentos y recursos legales propios de cada procedimiento ordinario, es procedente de manera excepcional la acción de tutela contra providencias judiciales que "sirve como instrumento para introducir la perspectiva de los derechos fundamentales a juicios tradi-

13 "Una sentencia hito es una sentencia que tiene un peso estructural fundamental dentro de una línea jurisprudencial por contener un caso que ha tenido consecuencias conceptuales profundas y duraderas en su configuración". "Una sentencia hito es aquella que pertenece al repertorio frecuente de sentencias que la Corte cita en fallos subsiguientes y que, proveen la retórica y marco de análisis en el tema concreto que se estudia”. López (2006), pp. 162, 171.

14 Corte Constitucional de Colombia, Sentencias SU-1219 de 2001; T-354 de 2002; C-590 de 2005; T-509 de 2006; SU-026 de 2012; T-208 de 2013; SU-055 de 2015; T-208 de 2017; T-406 de 2017.

15 Bernal (2006), pp. 228-229.

16 Corte Constitucional de Colombia, Sentencia T-774 de 2004.

17 Corte Constitucional de Colombia, Sentencia SU-1219 de 2001. 
cionalmente tramitados y definidos, exclusivamente, desde la perspectiva del derecho legislado" 18 .

En el segundo evento, la Constitución Política de 1991 en su artículo 86 consagró los instrumentos procesales para corregir los errores de la justicia constitucional: "el fallo que será de inmediato cumplimiento, podrá impugnarse ante el juez competente y, en todo caso, éste lo remitirá a la Corte Constitucional para su eventual revisión". De esta manera, la posibilidad de impugnar la sentencia de instancia ${ }^{19}$ y la eventual revisión de las sentencias de tutela ${ }^{20}$, son para la Corte Constitucional mecanismos idóneos y suficientes para corregir los errores judiciales que se presenten en el trámite del proceso de tutela.

La Corte Constitucional entiende que "la impugnación se constituye en un derecho fundamental constitucional y, por tanto, de obligatorio cumplimiento por el funcionario judicial, puesto que así se garantiza el debido proceso y el principio de la doble instancia" 21 . Por esta razón, la negativa arbitraria de admitir y tramitar la impugnación de la sentencia de instancia constituye, en sí misma, una vulneración a los derechos fundamentales al acceso a la administración de justicia $^{22}$, debido proceso $^{23}$ y petición ${ }^{24}$.

La eventual revisión que la Corte Constitucional realiza a las decisiones judiciales proferidas en el proceso de tutela garantiza en todos los escenarios constitucionales posibles un proceso especial contra cualquier falta de protección de los derechos fundamentales. Por lo cual su finalidad no es "solo unificar la interpretación constitucional en materia de derechos fundamentales, sino erigir a la Corte Constitucional como máximo tribunal de derechos constitucionales y como órgano de cierre de las controversias sobre el alcance de los mismos" 25 . Una vez finalizado el proceso de selección y de revisión de una sentencia de tutela, se genera su ejecutoria formal y material y opera el fenómeno de la cosa

\footnotetext{
18 Corte Constitucional de Colombia, sentencia C-590 de 2005.

19 Artículo 86 Constitución Política de Colombia; artículo 31 del Decreto No 2.591 de 1991.

20 Artículos 86 y 241, numeral 9 Constitución Política de Colombia.

21 Corte Constitucional de Colombia, sentencia T-633 de 2017.

22 Artículo 229 Constitución Política de Colombia.

23 Artículo 29 Constitución Política de Colombia.

24 Artículo 23 Constitución Política de Colombia.

25 Corte Constitucional de Colombia, sentencias SU-1219 de 2011; SU-055 de 2015.
} 
juzgada constitucional sin que sea posible reabrir el debate sobre lo decidido y la sentencia se torna inmutable, definitiva y vinculante ${ }^{26}$.

La cosa juzgada tiene dos consecuencias jurídicas relevantes para garantizar seguridad y estabilidad a las decisiones judiciales:

"Una de naturaleza positiva, cual es el de vincular o constreñir al juez para que reconozca y acate el pronunciamiento anterior (principio de la res judicata pro veritate habetur), y otra de connotación negativa, que se traduce en la prohibición que se impone también al operador jurídico para resolver sobre el fondo de conflictos ya decididos a través de sentencia en firme, evitando además que respecto de una misma cuestión litigiosa se presenten decisiones contradictorias con la primera. En este segundo efecto, lo que se pretende es no solo excluir una decisión contraria a la precedente, sino también cualquier nueva decisión sobre lo que ya ha sido objeto de juzgamiento anterior ${ }^{27}$ ".

La diferencia entre la cosa juzgada ordinaria y la cosa juzgada constitucional, radica en que esta última surge cuando finaliza el trámite de selección y revisión de las sentencias de tutela por parte de la Corte Constitucional. Por su parte, la cosa juzgada ordinaria tiene relación directa con la existencia de recursos judiciales y su resolución por parte del juez competente de la correspondiente jurisdicción. Sin embargo, las dos generan las mismas consecuencias jurídicas: que una decisión judicial adquiera los efectos de inmutable, definitiva, vinculante y coercitiva. De esta manera, la cosa juzgada constitucional es una especie dentro del género de la cosa juzgada ordinaria ${ }^{28}$.

Por lo anterior, en ningún escenario constitucional es procedente interponer una acción de tutela contra una sentencia de tutela que: (i) pueda impugnarse; (ii) esté en trámite de impugnación y de decisión en segunda instancia; (iii) esté en trámite de selección y de revisión en la Corte Constitucional y, (iv) el trámite de selección y de revisión haya finalizado, bien porque la Corte Constitucional la seleccionó, estudió y decidió o porque fue excluida de la selección para su revisión; operando en ambos casos el fenómeno de la cosa juzgada constitucional. Un juez constitucional que desconozca estos lineamientos jurisprudenciales

\footnotetext{
26 Nisimblat (2009), pp. 252, 257-259; Moreno (2018), pp. 14, 18; Corte Constitucional de Colombia, sentencia C-100 de 2019.

27 Corte Constitucional de Colombia, sentencia C-622 de 2007.

28 Corte Constitucional de Colombia, sentencia C-622 de 2007.
} 
suplantaría la competencia exclusiva de la Corte Constitucional para revisar las decisiones judiciales proferidas en el trámite del proceso de tutela ${ }^{29}$.

En palabras de la Corte Constitucional:

"Es claro que esta Corporación no admite ni considera procesalmente viables las tutelas contra sentencias de tutela que han hecho tránsito a cosa juzgada constitucional; ya que las posibles equivocaciones o arbitrariedades de los jueces que las fallen se deben plantear a través del mecanismo de revisión que corresponde únicamente a la Corte Constitucional, en aras de garantizar principios como la seguridad jurídica y el efectivo acceso a la administración de justicia"30.

La Corte Constitucional ha reconocido la posibilidad de que, en el trámite de selección de las sentencias de tutela para su revisión, se pueda incurrir en una equivocación al excluir un fallo que contenga un grave error judicial que vulnere derechos fundamentales de las partes involucradas en el proceso ${ }^{31}$. Sin embargo, para la Corte Constitucional, esta es una posibilidad ocasional y excepcional que es admisible y razonable comparada con la posibilidad de admitir la acción de tutela contra sentencias de tutela ${ }^{32}$.

La eventual revisión de las sentencias de tutela permite que las partes interesadas en su revisión presenten solicitudes argumentando los motivos que justifican su selección. De igual manera, cualquier Magistrado titular o directamente el Procurador General de la Nación, el Defensor del Pueblo o la Agencia Nacional de Defensa Jurídica del Estado, puede insistir en la selección de uno o más expedientes de tutela para su revisión ${ }^{33}$, circunstancia que refuerza la efi-

29 Corte Constitucional de Colombia, sentencia T-307 de 2015.

30 Corte Constitucional de Colombia, sentencia T-208 de 2013.

31 Si bien la selección de las sentencias de tutela continúa teniendo un carácter discrecional, el actual Reglamento de la Corte Constitucional establece los siguientes criterios orientadores de selección: (i) criterios objetivos: unificación de jurisprudencia, asunto novedoso, necesidad de pronunciarse sobre una determinada línea jurisprudencial, exigencia de aclarar el contenido y alcance de un derecho fundamental, posible violación o desconocimiento de un precedente de la Corte Constitucional; (ii) criterios subjetivos: urgencia de proteger un derecho fundamental o la necesidad de materializar un enfoque diferencial y, (iii) criterios complementarios: lucha contra la corrupción, examen de pronunciamientos de instancias internacionales judiciales o cuasi judiciales, tutela contra providencias judiciales en los términos de la jurisprudencia constitucional, preservación del interés general y grave afectación del patrimonio público. Artículo 52 del Acuerdo 002 de 2015.

32 Corte Constitucional de Colombia, sentencias SU-1219 de 2011; C-037 de 1996.

33 Artículo 57 del Acuerdo 002 de 2015. 
cacia e idoneidad de dicho mecanismo constitucional. Por esta razón, la Corte Constitucional manifestó:

"La cosa juzgada constitucional que se deriva del mecanismo de eventual revisión de los fallos de tutela impide que con posterioridad a la ejecutoria de la sentencia de tutela revisada por la Corte Constitucional o excluida de la selección para su revisión se tramite un nuevo proceso de tutela que presente: (i) identidad jurídica de partes; (ii) verse sobre el mismo objeto, es decir, sobre las mismas pretensiones y, (iii) se adelante por la misma causa que originó el proceso anterior, esto es, por los mismos hechos"34.

La acción de tutela se encuentra condicionada a los parámetros de la cosa juzgada con el fin de no reabrir las controversias que ya han sido decididas por la justicia constitucional, garantizando la seguridad jurídica de las decisiones judiciales y evitando que los problemas constitucionales se prolonguen de manera excesiva, alargando innecesariamente el debate sobre el contenido, alcance y exigibilidad de los derechos fundamentales que han sido objeto del proceso de tutela.

La Corte Constitucional también argumenta la improcedencia de la acción de tutela contra sentencias de tutela en la posible actuación temeraria que alguna de las partes pueda realizar al presentar varias acciones de tutela con identidad subjetiva, fáctica y de pretensiones que reúna una de las siguientes causales:

“(i) envuelva una actuación amañada, reservando para cada acción aquellos argumentos o pruebas que convaliden sus pretensiones ${ }^{35}$; (ii) denote el propósito desleal de obtener la satisfacción del interés individual a toda costa, jugando con la eventualidad de una interpretación judicial que, entre varias, pudiera resultar favorable ${ }^{36}$; (iii) deje al descubierto el abuso del derecho porque deliberadamente y sin tener razón, de mala fe se instaura la acción ${ }^{37}$ y, (iv) se pretenda a través de personas inescrupulosas asaltar la buena fe de los administradores de justicia"38 .

\footnotetext{
34 Corte Constitucional de Colombia, sentencias C-774 de 2001; T-019 de 2016; T-427 de 2017.

35 Corte Constitucional de Colombia, sentencia T-149 de 1995.

36 Corte Constitucional de Colombia, sentencia T-108 de 1995.

37 Corte Constitucional de Colombia, sentencia T-443 de 1995.

38 Corte Constitucional de Colombia, sentencia T-001 de 1997.
} 
La temeridad se configura únicamente cuando el actor del proceso de tutela ha obrado con mala fe, deslealtad procesal o su actuación ha infringido el deber de moralidad procesal ${ }^{39}$. Por esta razón, el Decreto № 2.591 de 1991 le confiere al juez constitucional la facultad de rechazar o decidir desfavorablemente todas las solicitudes del accionante temerario, sin perjuicio de las sanciones económicas previstas en el Código General del Proceso-Ley No 1.564 de 2012 y las sanciones disciplinarias por falta a la ética profesional consagradas en el Código Disciplinario del Abogado-Ley No 1.123 de 2007.

La Corte Constitucional argumenta la improcedencia de la acción de tutela contra sentencias de tutela con las siguientes razones:

"(i) admitirlo implicaría instituir un recurso adicional para insistir en la revisión de tutelas que con anterioridad no fueron seleccionadas; (ii) supondría crear una cadena interminable de demandas, con lo cual resultaría afectado el principio de seguridad jurídica; (iii) se afectaría el mecanismo de cierre hermenéutico de la Constitución, confiado a la Corte Constitucional y, (iv) el amparo perdería además como tal su efectividad jurídica, ya que entonces la misma quedaría indefinidamente postergada hasta que el vencido en un proceso de tutela decidiera no insistir en presentar otra tutela contra el fallo que le fue adverso para buscar que su posición coincida con la opinión de algún juez. En este evento, seguramente el anteriormente triunfador iniciará la misma cadena de intentos hasta volver a vencer. Si un juez de tutela incurre en una arbitrariedad o afecta el debido proceso mediante una vía de hecho, el remedio para estos problemas es el mecanismo de eventual revisión ante la Corte Constitucional, consagrado en el artículo 241 Superior” ${ }^{\prime} 0$.

\section{EL PRECEDENTE CONSTITUCIONAL VIGENTE Y APLICABLE} A PARTIR DE LA SENTENCIA SU-627 DE 2015

El precedente constitucional desarrollado por medio de la sentencia SU-1219 de 2001, consolidado y reiterado en varias sentencias posteriores, especialmente en las sentencias C-590 de 2005 y SU-055 de 2015, continúa vigente y aplicable. Sin embargo, a partir de la sentencia SU-267 de 2015, la Corte Constitucional estableció un escenario constitucional de procedencia excepcional de la acción de tutela contra sentencias de tutela, argumentado en la existencia de una situación

39 Corte Constitucional de Colombia, sentencias C-054 de 1993; SU-713 de 2006.

40 Corte Constitucional de Colombia, sentencias SU-1219 de 2001; SU-055 de 2015. 
de fraude que configure el fenómeno de la cosa juzgada fraudulenta, siempre y cuando, además de cumplir con los requisitos generales de procedibilidad de la acción de tutela contra providencias judiciales, se verifiquen los siguientes requisitos específicos:

“(i) la acción de tutela presentada no comporte identidad procesal con la solicitud de amparo cuestionada; (ii) se demuestre de manera clara y suficiente, que la decisión adoptada en la sentencia de tutela fue producto de una situación de fraude y, (iii) no exista otro medio, ordinario o extraordinario, eficaz para resolver la situación” ${ }^{4}$.

Este excepcionalísimo escenario constitucional no es procedente cuando la acción de tutela se interponga en contra de sentencias proferidas por la Corte Constitucional, sea por su Sala Plena o por sus Salas de Revisión de Tutela, debido a que para tal fin solo procede el incidente de nulidad de dichas sentencias que debe promoverse ante la misma Corte Constitucional ${ }^{42}$.

De esta manera, a pesar de que una sentencia de tutela haya adquirido el efecto formal y material de cosa juzgada constitucional por no haber sido seleccionada para su revisión por la Corte Constitucional, es posible solicitar su posterior y excepcionalísima revisión por medio de la presentación de una nueva acción de tutela, cuando se argumente razonable y objetivamente la existencia de una situación de fraude que amerite la intervención de la justicia constitucional.

\subsection{Requisitos especificos de procedencia de la acción de tutela contra sentencias de tutela}

Actualmente la sentencia SU-627 de 2015 es la sentencia dominante ${ }^{43}$ que resuelve el problema jurídico de la procedencia excepcional de la acción de tutela contra sentencias de tutela. A continuación, se desarrollan las subreglas vigentes o normas controlantes del caso fijadas por la Corte Constitucional en esta providencia judicial.

\footnotetext{
41 Corte Constitucional de Colombia, sentencia SU-627 de 2015.

42 Corte Constitucional de Colombia, sentencias T-282 de 2009; SU-627 de 2015.

43 Una sentencia dominante es una sentencia que contiene la respuesta correcta para un problema jurídico determinado, por lo cual establece los criterios vigentes y aplicables por medio de los cuales la Corte Constitucional resuelve un conflicto de intereses dentro de un determinado escenario constitucional. López (2006), pp. 162, 165.
} 


\subsubsection{La acción de tutela presentada no comporte identidad procesal con la sentencia de tutela cuestionada}

Los jueces son autoridades públicas que ejercen la función de administrar justicia, por lo cual sus decisiones son obligatorias para los particulares y los órganos del Estado. Sin embargo, la Corte Constitucional ha admitido la procedencia excepcional de la acción de tutela contra las decisiones de los jueces, cuando incurran en graves errores incompatibles con la Constitución que afecten los derechos fundamentales de las partes involucradas en el proceso judicial. Esta procedencia es calificada como excepcional con el fin de que no se desconozcan los principios de cosa juzgada, autonomía e independencia judicial, seguridad jurídica y la naturaleza subsidiaria que caracteriza a la acción de tutela ${ }^{44}$.

La Corte Constitucional ha distinguido dos partes constitutivas de la parte resolutoria de las sentencias de tutela: (i) la decisión de amparo y, (ii) la orden específica y necesaria para garantizar el goce del derecho protegido. Respecto de la decisión, el principio de cosa juzgada se aplica en términos absolutos conforme a la inimpugnabilidad que la caracteriza; mientras que, respecto de la orden se ha dicho que puede ser complementada para lograr el cabal cumplimiento del fallo. En este sentido, al verificarse la existencia de una situación de fraude que afecte la sentencia de tutela que no fue seleccionada por la Corte Constitucional para su revisión, la justicia constitucional no puede revocar esa providencia, lo que implicaría hacer un análisis de fondo de la misma y transgredir las consecuencias de la cosa juzgada constitucional que se producen una vez finalizado el trámite de revisión en esta Corporación. Sin embargo, sí puede hacer que esa decisión quede sin ningún valor jurídico, respetando la prohibición del non bis in idem, fundamentando su actuación en el precepto fraus omnia corrumpit (el fraude lo corrompe todo $)^{45}$.

La parte actora de la excepcional acción de tutela contra sentencias de tutela no puede olvidar que su pretensión solo puede estar encaminada exclusivamente a dejar sin efectos la sentencia de tutela cuestionada por presentar una situación de fraude que configure el fenómeno de la cosa juzgada fraudulenta que "se predica de un proceso que ha cumplido formalmente con todos los

44 Corte Constitucional de Colombia, sentencias C-590 de 2005; T-55 de 2009; T-244 de 2016.

45 Corte Constitucional de Colombia, sentencia SU-627 de 2015. 
requisitos procesales y que materializa, en esencia, un negocio fraudulento a través de medios procesales, que implica un perjuicio ilícito a terceros y a la comunidad" 46 .

Por lo cual el accionante no puede pretender que la justicia constitucional revoque la sentencia de tutela cuestionada porque, si bien se realiza un análisis y estudio de los hechos relevantes, el comportamiento de las partes y del juez, las pruebas y la decisión judicial adoptada, esta actividad cognoscitiva tiene como finalidad constitucional verificar la situación de fraude que permite la aplicación del principio fraus omnia corrumpit (el fraude lo corrompe todo) y no determinar cuál parte procesal tiene la razón en el proceso de tutela cuestionado.

De igual manera, el juez constitucional no puede dejar sin efectos la sentencia de tutela cuestionada cuando advierta que la finalidad del accionante es demostrar que los jueces de instancia erraron en la interpretación y resolución de la acción de tutela anterior, y que esta situación le causó perjuicios económicos que deben ser reparados. En este evento, el accionante "puede acudir a los medios de control respectivos ante la Jurisdicción de lo Contencioso Administrativo y solicitar las indemnizaciones correspondientes, pues se recuerda que la acción de tutela, además de ser subsidiaria, tiene un carácter eminentemente preventivo mas no indemnizatorio" ${ }^{47}$.

La Corte Constitucional reitera que el trámite de eventual revisión de las sentencias de tutela continúa siendo un control idóneo de los fallos de instancia que vulneran la Constitución. Por lo tanto, la procedencia de la acción de tutela contra sentencias de tutela es excepcional y está restringida únicamente a casos en los cuales se pruebe de manera clara y suficiente que la decisión adoptada en una anterior acción de tutela fue producto de una situación de fraude que atenta contra el ideal de justicia material. Es decir, la salvaguarda y garantía de los valores, principios y derechos fundamentales consagrados en la Constitución. La acción de tutela no puede utilizarse para reabrir el debate probatorio o sustantivo concluido por los jueces constitucionales en el trámite de la acción de tutela anterior ${ }^{48}$.

46 Corte Constitucional de Colombia, sentencia SU-627 de 2015.

47 Corte Constitucional de Colombia, sentencias T-031 de 2016; T-093 de 2018.

48 Corte Constitucional de Colombia, sentencia T-093 de 2018. 


\subsubsection{Se demuestre de manera clara y suficiente que la decisión} adoptada en la sentencia de tutela cuestionada fue producto de una situación de fraude (fraus omnia corrumpit)

De acuerdo con el precedente constitucional establecido a partir de la sentencia SU-627 de 2015, el único escenario constitucional que permite la procedencia excepcional de la acción de tutela contra sentencias de tutela, es la existencia de una situación de fraude que configure el fenómeno de la cosa juzgada fraudulenta y por ende permita la aplicación del principio fraus omnia corrumpit (el fraude lo corrompe todo); facultando a la justicia constitucional dejar sin efectos la sentencia de tutela cuestionada que no fue seleccionada por la Corte Constitucional para su revisión.

La Corte Constitucional reconoce que la regla de la improcedencia de la acción de tutela contra sentencias de tutela no es absoluta porque:

"El principio de cosa juzgada no puede entenderse en términos absolutos, pues en ciertas circunstancias, como cuando está de por medio el principio de fraus omnia corrumpit, puede entrar en tensión con el principio de justicia material, a partir del cual es posible desvirtuar la presunción de legalidad y acierto que tiene la decisión del juez" ${ }^{\prime 9}$.

Desde la sentencia T-006 de 1992 la Corte Constitucional ha indicado que toda decisión judicial debe respetar un mínimo de justicia material, entendida como el deber judicial de incorporar y garantizar en la sentencia la salvaguarda de los valores y principios constitucionales y la tutela judicial efectiva de los derechos fundamentales de las partes involucradas en el proceso. Por esta razón, una sentencia que no garantice estos contenidos materiales de especial protección constitucional no puede hacer tránsito a cosa juzgada material. Ante la constatación de una situación de fraude que configure el fenómeno de la cosa juzgada fraudulenta, la justicia constitucional está facultada para dejar sin efectos la sentencia de tutela cuestionada argumentando su decisión en la aplicación del principio fraus omnia corrumpit (el fraude lo corrompe todo).

En palabras de la Corte Constitucional:

"No se trata de una mecánica y formal aplicación del derecho a los hechos. La Constitución pretende que el juez -obligado portador de los principios y valores

49 Corte Constitucional de Colombia, sentencia T-218 de 2012. 
incorporados positivamente al texto constitucional-al decidir la controversia busque materializar en el mayor grado posible tales principios y valores de modo que su sentencia asegure la convivencia pacífica y la vigencia de un orden justo. En la sociedad democrática que establece la Constitución, la misión del juez se concreta en la de ser un instrumento eficaz de justicia material. Aparte de los criterios constitucionales aplicables a la tramitación y decisión de los procesos, cuya finalidad es incorporar a la sentencia el máximo de contenido de justicia, la Constitución determina un ámbito que representa el mínimo de justicia material que ella debe contener y que en ningún caso puede sacrificarse en aras de la seguridad jurídica. Este ámbito merecedor de tan especial protección corresponde a los derechos fundamentales cuya afectividad se eleva a fin esencial del Estado y a razón de ser de sus autoridades" 50 .

Antes de que la Sala Plena de la Corte Constitucional por medio de la sentencia SU-627 de 2015 unificara la jurisprudencia con relación a la procedencia excepcional de la acción de tutela contra sentencias de tutela, algunas Salas de Revisión de Tutela mediante las sentencias T-218 de 2012, T-951 de 2013, T-272 de 2014 y T-373 de 2014 ya se habían pronunciado en favor de esta posibilidad indicando que su procedibilidad está limitada exclusivamente a revertir o detener situaciones fraudulentas y graves ocasionadas por el cumplimiento de una orden proferida en un proceso de tutela.

La sentencia T-218 de 2012 puede catalogarse como una sentencia hito fundadora de línea, debido a que es la que fundamenta doctrinariamente la sentencia SU-627 de 2015, brindando el marco de análisis del tema concreto que se estudia. Aunque en su momento la sentencia SU-055 de 2015 le quitara su fuerza normativa vinculante al reiterar el precedente constitucional establecido en la sentencia SU-1219 de 2001, la sentencia SU-627 de 2015 le devolvió su peso estructural fundamental, dentro de la línea jurisprudencial que actualmente contiene las subreglas vigentes o normas controlantes del caso que permiten resolver los procesos de tutela contra sentencias de tutela.

Sin embargo, es la sentencia SU-627 de 2015 la que permite la procedencia excepcional de la acción de tutela contra sentencias de tutela, debido a que solo la Sala Plena de la Corte Constitucional puede cambiar el precedente constitucional aplicable con relación al contenido y alcance de los derechos fundamentales. Por lo tanto, la Corte Constitucional en la sentencia SU-627 retoma las subreglas jurisprudenciales fijadas implícitamente en la sentencia T-218 de 2012, las cuales

50 Corte Constitucional de Colombia, sentencia T-006 de 1992. 
constituyen los actuales y vigentes requisitos específicos de procedencia de la acción de tutela contra sentencias de tutela.

Las sentencias T-951 de 2013, T-272 de 2014 y T-373 de 2014 concuerdan en que fue la sentencia T-218 de 2012 la que estableció implícitamente las subreglas jurisprudenciales de procedencia excepcional de la acción de tutela contra sentencias de tutela que posteriormente la Corte Constitucional retomó en la sentencia SU-627 de 2015, como requisitos específicos de procedencia. Sin embargo, la sentencia T-951 de 2013 fue el primer fallo que identificó la ratio decidendi de la sentencia T-218 de 2012 haciendo explícitos estos requisitos específicos.

La sentencia SU-627 de 2015 representa un precedente constitucional reconceptualizado o reorientado doctrinariamente, debido a que redefine o refina hermenéuticamente el precedente constitucional existente, en el entendido de que con fundamento en pronunciamientos jurisprudenciales anteriores, específicamente en las sentencias T-218 de 2012, T-951 de 2013, T-272 de 2014 y T-373 de 2014, estableció una excepción a la regla general de improcedencia de la acción de tutela contra sentencias de tutela con la finalidad constitucional de garantizar la tutela judicial efectiva de los derechos fundamentales, en especial del derecho al debido proceso.

La Corte Constitucional realizó un análisis doctrinario del principio fraus omnia corrumpit (el fraude lo corrompe todo) señalando que la cosa juzgada fraudulenta y el fraude procesal son especies dentro del fraude en el derecho. En tal sentido precisó:

"La cosa juzgada fraudulenta se presenta cuando la actuación aviesa al derecho se materializa en la providencia, mientras que el fraude procesal no necesariamente se reviste o tiene la calidad de la cosa juzgada. En este sentido, para diferenciar ambos conceptos, Véscori plantea que la cosa juzgada fraudulenta se predica de un proceso que ha cumplido formalmente con todos los requisitos procesales y que materializa en esencia un negocio fraudulento a través de medios procesales, que implica un perjuicio ilícito a terceros y a la comunidad.

(...) según Carnelutti, el objetivo del fraude es desviar el proceso de su fin: resolver conforme a justicia la controversia humana. En cambio, para Véscori el fin del fraude es precisamente la cosa juzgada que, al darle seguridad y certeza a la consecuencia jurídica buscada, la hace difícil de combatir, permitiendo incluso que sea exigible de manera coactiva. Pero, en todo caso, sin importar desde cuál de estas perspectivas doctrinarias se analice, lo cierto es que "el dolo se sirve de la justicia para alcanzar sus fines". Por ello, sancionar y desvirtuar la cosa juzgada fraudulenta supone re- 
parar a la sociedad en su conjunto, pues el dolo atenta contra el bien social de la administración de justicia" 51 .

Por lo anterior, "la cosa juzgada fraudulenta se predica cuando el dolo se ha materializado en la sentencia judicial" 52 . Para que la justicia constitucional acredite la existencia de una cosa juzgada fraudulenta ${ }^{53}$ que afecta la sentencia de tutela cuestionada no es necesario que represente una conducta punitiva enjuiciable penalmente, basta con su demostración procesal y probatoria, debido a que el objeto del fraude supone logar que una situación dolosa sea exigible judicialmente por medio de la coercibilidad de la sentencia.

Una vez que el juez constitucional constate la existencia de una situación de fraude que afecte la sentencia de tutela cuestionada, estará facultado para dejar sin efectos dicha providencia y remitir copias de su decisión a la Fiscalía General de la Nación y al Consejo Superior de la Judicatura para que adelanten las investigaciones penales y disciplinarias de su competencia.

No se trata de respetar la cosa juzgada constitucional por su aspecto netamente procesal sino por su finalidad que obedece a la protección de los derechos fundamentales. El desconocimiento de esta finalidad constitucional amerita la intervención de la justicia constitucional, debido a que no puede consolidarse una situación injusta contraria a derecho. Esta tensión entre la legalidad y la legitimidad de una decisión judicial genera un problema ético de validez porque la cosa juzgada constitucional representa una pretensión de justicia del derecho. La cosa juzgada, incluso la constitucional, "no es un fin en sí mismo, sino un medio para alcanzar el valor de la justicia. Por tanto, no es un principio absoluto del derecho, sino un elemento que integra la pretensión de corrección del mismo" 54 .

\footnotetext{
51 Corte Constitucional de Colombia, sentencia T-218 de 2012.

52 Corte Constitucional de Colombia, sentencia T-218 de 2012.

53 La Corte Interamericana de Derechos Humanos ha establecido que la cosa juzgada fraudulenta se presenta cuando en el trámite de un proceso judicial no se respetan las garantías del debido proceso o cuando los jueces no actúan con independencia e imparcialidad. Por lo cual, propone como mecanismos normativos para contrarrestar esta práctica inadecuada: (i) el deber de los Estados de prevenir la falta de garantías judiciales; (ii) la necesaria independencia del juez que trámite el proceso; (iii) la garantía de instrucción y resolución imparcial del proceso por medio de una correcta motivación y, (iv) la inobservancia del non bis in idem cuando se presenta una cosa juzgada fraudulenta. CHACón (2015), pp. 174, 176-180.
}

54 Corte Constitucional de Colombia, sentencia T-951 de 2013. 
La existencia de una situación de fraude que configure el fenómeno de la cosa juzgada fraudulenta representa una flagrante vulneración al derecho fundamental al debido proceso porque no permite materializar la tutela judicial efectiva de los derechos fundamentales y desnaturaliza la función constitucional del servicio público de administración de justicia. En tal sentido, la situación de fraude atenta contra el principio de buena fe, lealtad y moralidad procesal ${ }^{55}$ y el deber constitucional de colaborar con el buen funcionamiento de la administración de la justicia ${ }^{56}$.

\subsubsection{No exista otro medio ordinario o extraordinario eficaz para resolver la situación cuestionada}

Este requisito hace referencia al principio de subsidiaridad de la acción de tutela consagrado en el artículo 86 Superior que indica: "esta acción sólo procederá cuando el afectado no disponga de otro medio de defensa judicial, salvo que aquella se utilice como mecanismo transitorio para evitar un perjuicio irremediable".

La acción de tutela contra sentencias de tutela no es procedente cuando el accionante pretenda sustituir los mecanismos jurídicos establecidos para corregir los posibles errores de la justicia constitucional porque para estos eventos la Constitución, en su artículo 86, consagró la posibilidad de impugnar el fallo de tutela y la eventual revisión por parte de la Corte Constitucional de las decisiones judiciales proferidas en el proceso de tutela.

La procedencia excepcional de la acción de tutela contra sentencias de tutela no tiene como finalidad corregir los posibles errores de la justicia constitucional. Su procedencia está argumentada exclusivamente en la necesidad de revertir situaciones fraudulentas que ameriten la aplicación del principio fraus omnia corrumpit (el fraude lo corrompe todo) y, por tanto, dejar sin efectos la sentencia de tutela no seleccionada para su revisión por parte de la Corte Constitucional. El efecto formal y material de cosa juzgada constitucional debe ceder ante la existencia de dicha situación de fraude denominada cosa juzgada fraudulenta ${ }^{57}$.

55 Artículo 83 Constitución Política de Colombia.

56 Artículo 95, numeral 7 Constitución Política de Colombia.

57 Corte Constitucional de Colombia, sentencia SU-627 de 2015. 
Este requisito de subsidiaridad de la acción de tutela tiene como objetivo garantizar el respeto por el proceso judicial de tutela, debido a que las etapas, procedimientos y recursos que conforman este proceso representan el espacio e instrumentos de protección de los derechos fundamentales, en especial de las garantías constitucionales del debido proceso.

La Corte Constitucional ha sido enfática al establecer que:

"Tratándose de instrumentos dirigidos a la preservación de los derechos, el medio judicial por excelencia es el proceso, tal como lo acreditan sus remotos orígenes. Por tanto, no es admisible que el afectado alegue la vulneración o amenaza de un derecho fundamental cuando no ha solicitado el amparo de sus derechos dentro del proceso, pues, en principio, el ordenamiento jurídico le ha dotado de todas las herramientas necesarias para corregir durante su trámite las irregularidades procesales que puedan afectarle" 58 .

El juez constitucional en el estudio de la admisibilidad de la acción de tutela contra sentencias de tutela debe verificar si el trámite de eventual revisión del fallo cuestionado ya finalizó en la Corte Constitucional y si el accionante ha intervenido en éste por medio de la solicitud de selección de su caso. De lo contrario estaría presumiendo, en abstracto, la ineficacia y la no idoneidad de los mecanismos jurídicos establecidos por la Constitución para corregir los posibles errores de la justicia constitucional59.

\subsubsection{No es procedente cuando la acción de tutela se interponga en contra de sentencias proferidas por la Corte Constitucional}

La acción de tutela contra sentencias de tutela no procede en contra de las sentencias proferidas por la Corte Constitucional, sea por su Sala Plena o por sus Salas de Revisión de Tutelas, debido a que para tal fin solo procede de manera excepcional el incidente de nulidad que se debe tramitar ante la misma Corte Constitucional siempre y cuando se demuestre que se incurrió en irregularidades que vulneraron el derecho fundamental al debido proceso. Por lo cual, el incidente de nulidad no es un recurso, ni una nueva oportunidad para reabrir el debate probatorio o revisar controversias que ya fueron decididas ${ }^{60}$.

58 Corte Constitucional de Colombia, sentencia C-543 de 1992.

59 Corte Constitucional de Colombia, sentencia T-093 de 2018.

60 Corte Constitucional de Colombia, sentencias T-282 de 2009; SU-627 de 2015. 
Los siguientes son los requisitos de contenido formal y material que deben satisfacerse para interponer un incidente de nulidad en contra de una sentencia proferida por la Corte Constitucional ${ }^{61}$.

Requisitos formales: las solitudes de nulidad deben cumplir todos y cada uno de los siguientes requisitos de procedibilidad a fin de que puedan ser objeto de estudio y análisis:

(i) Temporalidad: si la nulidad tiene origen en la sentencia, el incidente debe proponerse dentro de los tres días siguientes, contados a partir de la notificación de la sentencia. Si la nulidad está fundada en un vicio anterior al fallo solo podrá ser alegada antes de proferida la sentencia.

(ii) Legitimación en la causa por pasiva: debe ser propuesto por quien haya sido parte en el trámite del proceso constitucional o un tercero que resulte afectado con las órdenes proferidas en sede de revisión.

(iii) Deber de argumentación: quien alega la existencia de una nulidad debe cumplir con una exigente carga argumentativa a través de la cual explique, de forma clara, las disposiciones constitucionales transgredidas y la incidencia en la decisión proferida.

Requisitos materiales: la vulneración del derecho fundamental al debido proceso puede argumentarse cuando se incurra en alguna de estas causales:

(i) Cambio de jurisprudencia: se presenta cuando una de las Salas de Revisión cambia la jurisprudencia, desconociendo la competencia exclusiva de la Sala Plena de la Corte Constitucional para tal fin.

(ii) Desconocimiento de las mayorías: en los casos en los que la Corte Constitucional profiera una sentencia sin que haya sido aprobada por las mayorías exigidas en el Decreto No 2.067 de 1991 y la Ley No 270 de 1996.

(iii) Incongruencia entre la parte considerativa y resolutiva de la sentencia: esta causal se invoca en aquellos eventos en los cuales exista incertidumbre respecto de la decisión adoptada, como es el caso de las decisiones ininteligibles por abierta contradicción o cuando carece en su totalidad de argumentación en su parte motiva.

(iv) Órdenes dadas a particulares no vinculados al proceso de tutela: esta causal surge como garantía del derecho de defensa de aquellos que no intervinieron en el proceso de tutela.

61 Corte Constitucional de Colombia, Autos 217 de 2006; 048 de 2013; 347 de 2016. 
(v) Desconocimiento de la cosa juzgada constitucional: se presenta cuando la Corte Constitucional estudia y decide un caso ya resuelto en una sentencia anterior que presenta una identidad subjetiva, fáctica y de pretensiones que impide un nuevo pronunciamiento.

(vi) Elusión arbitraria de análisis de asuntos de relevancia constitucional: hay lugar a su viabilidad siempre y cuando los fundamentos utilizados resulten transcendentales para el sentido de la decisión. Se debe precisar que la Corte Constitucional cuenta con la facultad de estudiar cada caso, limitándose a los temas que considere presentan especial trascendencia. Por ello no es obligatorio para el juez constitucional resolver en detalle todos los aspectos planteados en el escrito de tutela, ya que la solicitud de nulidad no constituye una instancia adicional.

\subsection{Requisitos generales de procedencia de la acción de tutela contra sentencias de tutela}

Este presupuesto procesal exige el cumplimiento de los mismos requisitos generales de procedencia excepcional de la acción de tutela contra providencias judiciales $^{62}$ :

(i) Que la cuestión que se discuta resulte de evidente relevancia constitucional.

(ii) Que se hayan agotado todos los medios, ordinarios y extraordinarios, de defensa judicial al alcance de la persona afectada, salvo que se trate de evitar la consumación de un perjuicio ius-fundamental irremediable.

(iii) Que se cumpla el requisito de inmediatez, es decir que la acción de tutela se hubiere interpuesto en un término razonable y proporcionado a partir del hecho que originó la vulneración del derecho fundamental.

(iv) Cuando se trate de una irregularidad procesal, debe quedar claro que la misma tiene un efecto decisivo o determinante en la sentencia que se impugna y que afecta los derechos fundamentales de la parte actora.

(v) Que la parte actora identifique de manera razonable tanto los hechos que generaron la vulneración como los derechos vulnerados y que hubiere alegado tal vulneración en el proceso judicial siempre que esto hubiere sido posible.

62 Corte Constitucional de Colombia, sentencias C-590 de 2005; SU-026 de 2012; SU-198 de 2013; SU-297 de 2015; SU-659 de 2015. 


\section{LA CONSTITUCIONALIZACIÓN DEL DERECHO JURISPRUDENCIAL EN COLOMBIA}

La Constitución de 1991 consagra la acción de tutela como el instrumento procesal por excelencia para garantizar la salvaguarda y la efectividad de los derechos fundamentales. Sin embargo, la evolución de la teoría constitucional, los cambios socio-políticos y el empoderamiento ciudadano de los derechos fundamentales, han generado que a la hora de tramitar y decidir este instrumento procesal constitucional se presenten deficiencias metodológicas, entendidas como problemas interpretativos y argumentativos para construir la teoría y la decisión judicial del caso, que no pueden solucionarse conforme con las disposiciones constitucionales que regulan su consagración originaria en los artículos 86 y 241 \#9 Superiores.

Es necesario que la Corte Constitucional por medio de su jurisprudencia, cree remedios judiciales que aseguren el fin constitucional de la acción de tutela. Con tal finalidad, a partir de la sentencia SU-627 de 2015, la Corte Constitucional fijó las subreglas vigentes o normas controlantes del caso que permiten la procedencia excepcional de la acción de tutela contra sentencias de tutela.

En Colombia no existe la "regla de reiteración"63 de la jurisprudencia para que las sentencias de la Corte Constitucional adquieran un carácter vinculante y obligatorio para los demás jueces constitucionales. Sin embargo, la reiteración de una sentencia sí hace que la línea jurisprudencial que se construye a partir de ésta se consolide y sea estable. En tal sentido, el precedente constitucional fijado en la sentencia SU-627 de 2015 se puede calificar como estable y consolidado, o por lo menos con dicha pretensión, porque ha sido reiterado recientemente en las sentencias T-591 de 2016, T-427 de 2017, T-633 de 2017, T-072 de 2018, T-093 de 2018 y T-322 de 2019.

Este precedente constitucional permite afirmar que la procedencia excepcional de la acción de tutela contra sentencias de tutela es una manifestación de la constitucionalización del derecho jurisprudencial en Colombia. Este fenómeno jurídico puede explicarse con las siguientes tres características: (i) la reconfiguración del sistema de fuentes del derecho; (ii) la incorporación de nuevos métodos de interpretación y, (iii) la apertura a nuevas formas de litigio constitucional.

63 "Puede definirse la 'regla de reiteración' como la obligación que tiene una Corte de cierre de reiterar una determinada doctrina (hasta el punto de lograr su estabilidad) antes de exigirle a los demás jueces de su jurisdicción que consideren el precedente vinculante”. LópEz (2006), p. 145. 


\subsection{La reconfiguración del sistema de fuentes del derecho}

La constitucionalización del derecho implica que la Constitución se convierte en la norma jurídica primera del ordenamiento jurídico. Transformación jurídica que permite entender el fenómeno de la constitucionalización del derecho como un proceso de juridificación y de judicialización de la Constitución ${ }^{64}$.

El proceso de juridificación de la Constitución permite aprehenderla en tanto norma jurídica suprema, vinculante y de aplicación directa que configura el orden jurídico-político básico de la sociedad ${ }^{65}$. La Constitución se convierte en la fuente primera del derecho y en el criterio de validez formal y material de todo el ordenamiento jurídico, debido a que su función selectiva y de límite no solo establece la competencia y procedimientos generales para el cumplimiento de las funciones de los poderes públicos, sino que exige la salvaguarda y efectividad de los valores, principios y derechos fundamentales ${ }^{66}$.

El proceso de judicialización exige que la Constitución cuente con una garantía de defensa jurisdiccional por parte del Tribunal Constitucional que la protege de las voluntades políticas del legislador y del poder ejecutivo, garantizando su integridad y supremacía sobre todas las normas del ordenamiento jurídico ${ }^{67}$.

Este proceso de judicialización de la Constitución ha generado que la jurisprudencia de la Corte Constitucional adquiera un nuevo papel y ubicación en el sistema de fuentes del derecho colombiano, debido a que por su condición de Tribunal de cierre en materia de interpretación y determinación del contenido y del alcance de los derechos fundamentales, su precedente constitucional adquiere un carácter vinculante y obligatorio para los particulares y todas las entidades públicas.

"Junto al texto de la Constitución, antaño fuente indisputada de todo el derecho constitucional, hoy en día aparece el juez constitucional, a través de su jurisprudencia, como creador consciente de subreglas constitucionales y no simplemente como un aplicador pasivo de los textos superiores"68.

\footnotetext{
64 Restrepo (2018), pp. 46-49.

65 Restrepo (2015), pp. 43-58.

66 De Оtтo (1987), pp. 39-41; Guastini (2003), pp. 50-58; Ferrajoli (2003), pp. 18-20.

$67 \operatorname{Kelsen}(1993 ; 1995)$.

68 López (2006), pp. xix-xx.
} 
Actualmente, la mayoría de los problemas constitucionales no se resuelven exclusivamente acudiendo a las disposiciones constitucionales. Es necesario identificar las subreglas vigentes o normas controlantes del caso fijadas por la Corte Constitucional. Este es el caso de la procedencia excepcional de la acción de tutela contra sentencias de tutela que no se puede deducir de la simple lectura de los artículos 86 y 241 \# 9 de la Constitución Política de 1991. "Así, el sistema de fuentes se abre hacia una mezcla efectiva entre textos positivos y derecho jurisprudencial, sin que sea fácilmente discernible cuál de las dos fuentes del sistema sea la dominante" 69 .

Por medio del precedente constitucional la Corte Constitucional concretiza y desarrolla el alcance de una disposición constitucional. Explica qué es aquello que la Constitución prohíbe, permite, ordena o habilita en un determinado escenario constitucional a partir de la interpretación de su texto. Sin embargo, la atribución de la fuerza normativa vinculante de la jurisprudencia constitucional no ha tenido un reconocimiento claro y explícito en la Constitución ni en ninguna disposición legal ${ }^{70}$.

Fue un auto-reconocimiento jurisprudencial ${ }^{71}$ de la misma Corte Constitucional el que permitió que el precedente constitucional adquiriera su valor de fuente obligatoria del derecho que a su vez se incorpora e integra al texto constitucional. La jurisprudencia constitucional no es una fuente supletiva del derecho cuya aplicación pueda estar condicionada a la existencia de la vaguedad de una disposición legal, a la falta de coherencia o contradicción entre disposiciones legales o a la falta de plenitud del ordenamiento jurídico ${ }^{72}$. Por el contrario, la jurisprudencia constitucional es una fuente formal del derecho al igual que la Constitución y la ley.

En este sentido, es prudente citar la siguiente reflexión:

"Difícilmente puede imaginarse una auto-atribución de poder mayor que la que un órgano judicial se hace a sí mismo cuando sostiene que sus actos son una fuente del derecho que se integra en la Constitución, es decir, en la fuente de máxima jerarquía en el ordenamiento jurídico, y que, como tales, dichos actos deben ser obedecidos por todos los poderes públicos y privados y no pueden ser revisados sino por el

69 López (2006), p. 193.

70 Bernal (2005), pp. 151-157.

71 Corte Constitucional de Colombia, sentencias SU-047 de 1999; C-252 de 2001; C-836 de 2001.

72 Bernal (2005), pp. 151-157. 
propio órgano jurisdiccional. Desde esta óptica, el legislador habría pagado caro la falta de una regulación específica del precedente constitucional. El precio habría sido el desplazamiento de la ley, por parte de la jurisprudencia constitucional, del lugar de fuente prioritaria del derecho"73.

Esta reconfiguración del sistema de fuentes del derecho, donde el precedente constitucional se encuentra en la misma escala jerárquica de la Constitución, ha permitido que se proponga que la excepción de inaplicación por inconstitucionalidad $^{74}$, consagrada en el artículo 4 Superior, no solo se aplique para garantizar la supremacía del texto constitucional, sino que también se extienda su aplicación para garantizar el respeto por el precedente constitucional, debido a que el precedente constitucional es la Constitución misma, es decir es la concreción de aquello que la Constitución prescribe ${ }^{75}$. Por esta razón, en caso de incompatibilidad entre el precedente constitucional y una ley u otra norma de inferior jerarquía estas deberán implicarse y aplicarse correlativamente el precedente constitucional.

\subsection{La incorporación de nuevos métodos de interpretación}

La constitucionalización del derecho obliga a todo operador jurídico, independiente si es un particular o un funcionario público, a interpretar, argumentar y aplicar el significado axiológico de los contenidos materiales que conforman el núcleo esencial de la Constitución: valores ${ }^{76}$, principios ${ }^{77}$ y derechos fundamentales ${ }^{78}$.

En este proceso de interpretación del texto constitucional, se debe entender que las disposiciones constitucionales tienen una estructura jurídica diferente entre sí, debido a que no solo existen normas-reglas, sino y en mayor medida normasprincipios que exigen una actividad interpretativa y argumentativa diversa: las normas-reglas se interpretan y aplican por medio de la subsunción, mientras las normas-principios requieren de una ponderación a fin de establecer su grado

\footnotetext{
73 Bernal (2005), p. 155.

74 Usquiano (2017), pp. 73-84.

75 Bernal (2005), p. 189.

76 Vila (2009), p. 226.

77 ZagrebelsKy (1999), pp. 116-120.

78 Chinchilla (2010), p. 89.
} 
de aplicabilidad en el caso en concreto ${ }^{79}$. En este sentido, cuando estamos en presencia de los contenidos materiales de la Constitución, no es posible aplicar un criterio de validez o de aplicación del "todo o nada", sino que es necesario la identificación de las condiciones fácticas y jurídicas que permitan la mayor o menor aplicación de una norma con categoría de principio dependiendo de su peso e importancia en el específico escenario constitucional ${ }^{80}$.

La Constitución exige que los jueces realicen una interpretación, argumentación y aplicación del derecho que garantice la obtención del mayor grado de justicia material, entendida como la incorporación a la sentencia de los valores y principios constitucionales y la efectividad de los derechos fundamentales de las partes involucradas en el proceso, y no solo la aplicación estricta de las disposiciones legales que regulan el caso ${ }^{81}$.

La reconfiguración del sistema de fuentes del derecho exige una adecuada interpretación, argumentación y aplicación del precedente constitucional. Esto requiere la identificación de la parte vinculante del mismo, es decir, la ratio decidendi de la jurisprudencia constitucional. Para realizar esta actividad cognoscitiva es necesario reivindicar la plenitud del texto jurisprudencial conformada por tres partes: (i) hechos, (ii) consideraciones y, (iii) decisión; y no solo aceptar lecturas aisladas de sentencias donde no se logre identificar su ubicación dentro de una línea jurisprudencial. El precedente constitucional está argumentado en el principio de igualdad de trato que exige analizar los hechos relevantes, las circunstancias fácticas y las subreglas vigentes o normas controlantes del caso fijadas en la decisión judicial ${ }^{82}$.

La Corte Constitucional reconoce que el precedente constitucional debe ser construido hermenéuticamente cuando las lecturas textualistas no resulten satisfactorias para la resolución adecuada de los casos y sobre todo para la explicación sistemática de la línea jurisprudencial. Sin embargo, exige que las sentencias tengan argumentos claros y explícitos para que los jueces posteriores no tengan que recurrir a extensas reconstrucciones de la ratio decidendi implícita en ellas. La identificación de la ratio decidendi contenida en una sentencia depende de los hechos que se consideren relevantes en el proceso y del sentido del fallo.

79 Alexy (1994), pp. 167-172.

80 Pozzolo (1998), pp. 339-342.

81 Corte Constitucional de Colombia, sentencia T-006 de 1992.

82 LÓPEZ (2006), pp. 196-199. 
Por lo cual la ratio decidendi es el argumento jurídico explícito deducido de la lectura textualista de la sentencia o de la construcción hermenéutica que mejor une y explica los hechos relevantes del proceso y el sentido del fallo ${ }^{83}$.

El juez constitucional puede apartarse del precedente constitucional siempre y cuando presente una justificación suficiente, razonable y adecuada que permita demostrar que el cambio no es arbitrario, sino que está soportado en razones que tengan un peso y una importancia estructural que para el caso en concreto primen no solo sobre los criterios que sirvieron de base a la decisión en el pasado, sino también sobre las consideraciones de seguridad jurídica e igualdad que fundamentan el respeto al precedente constitucional.

\subsection{La apertura a nuevas formas de litigio constitucional}

De la lectura aislada del artículo 86 Superior se puede deducir que la acción de tutela permite dos formas de litigio constitucional: (i) contra autoridades públicas y, (ii) "contra particulares encargados de la prestación de un servicio público cuya conducta afecte grave y directa el interés colectivo, o respecto de quienes el solicitante se halle en estado de subordinación”.

Sin embargo, por medio de la jurisprudencia constitucional se ha dado la apertura a nuevas formas de litigo constitucional como lo son la acción de tutela contra providencias judiciales y recientemente contra sentencias de tutela. La Corte Constitucional reconoce la ocurrencia de posibles errores de la justicia constitucional que exigen la creación de remedios judiciales adecuados e idóneos que permitan corregirlos, en especial cuando se materializan en la sentencia y se camuflan en el efecto formal y material de la cosa juzgada constitucional. Tal es el caso de la situación de fraude que configura el fenómeno de la cosa juzgada fraudulenta que permite el único escenario constitucional de procedencia excepcional de la acción de tutela contra sentencias de tutela.

Este auto-reconocimiento puede ser la aplicación de las lecciones aprendidas del anterior paradigma del Estado legislativo de derecho donde se presentaba el mito del legislador sabio e infalible y el axioma dura lex sed lex. Por esta razón, la justicia constitucional se presenta a sí misma como una jurisdicción especializada con conocimiento y experiencia, pero sin negar la posibilidad de la existencia de eventuales errores judiciales que puedan vulnerar derechos fundamentales de las

83 López (2006), pp. 247-249. 
partes vinculadas al proceso de tutela. De esta manera, el único significado de "dureza" o "rigidez" de una sentencia de tutela debe ser el reconocimiento que hace una de las partes de que su pretensión no es constitucionalmente admisible y no que la decisión judicial incurre en un grave error que vulnera sus derechos fundamentales.

En el modelo del Estado legislativo de derecho ${ }^{84}$, el derecho nace y se consolida históricamente con la afirmación del principio de legalidad como criterio exclusivo de identificación del derecho válido con independencia de su valor como justo, por lo cual, una norma jurídica era válida no por ser justa, sino por haber sido creada por la autoridad dotada de competencia normativa para hacerlo ${ }^{85}$.

En el actual Estado constitucional y democrático de derecho, el derecho válido además de ser creado por la autoridad dotada de competencia normativa para hacerlo, está íntimamente relacionado con el valor-principio de la justicia material, entendida como la salvaguarda efectiva de los valores, de los principios y de los derechos fundamentales que conforman el núcleo esencial de la Constitución ${ }^{86}$. Por lo cual una sentencia que no garantice estos contenidos materiales que representan criterios normativos de especial protección constitucional, no puede hacer tránsito a cosa juzgada material. Circunstancia que permite activar las nuevas formas de litigo constitucional como lo son la acción de tutela contra providencias judiciales y la acción de tutela contra sentencias de tutela.

\section{CONCLUSiOnes}

La evolución de la teoría constitucional, los cambios sociales, económicos, políticos y jurídicos del país y el empoderamiento ciudadano de los derechos fundamentales, han generado que en el trámite de la acción de tutela, la justicia constitucional se enfrente a determinadas deficiencias metodológicas, entendidas como problemas interpretativos y argumentativos para construir la teoría y decisión judicial del caso, que no pueden solucionarse conforme con las disposiciones constitucionales que regulan la consagración originaria y expresa de la acción de tutela.

84 Capella (1997), p. 135.

85 Ferrajoli (2003), p. 16.

86 Corte Constitucional de Colombia, sentencias T-006 de 1992; T-406 de 1992. 
Es necesario que la Corte Constitucional por medio de su jurisprudencia, cree remedios judiciales para contrarrestar estas deficiencias metodológicas, con el objetivo de asegurar el fin constitucional de la acción de tutela: la protección judicial efectiva de los derechos fundamentales. Con tal finalidad, a partir de la sentencia SU-627 de 2015, la Corte Constitucional colombiana fija las subreglas vigentes o normas controlantes del caso que permiten la procedencia excepcional de la acción de tutela contra sentencias de tutela cuando se presente una situación de fraude que configure el fenómeno de la cosa juzgada fraudulenta, que faculta a la justicia constitucional a dejar sin efectos la sentencia de tutela cuestionada en aplicación del principio fraus omnia corrumpit (el fraude lo corrompe todo).

En la sentencia SU-627 de 2015 con fundamento en pronunciamientos jurisprudenciales anteriores, específicamente en las sentencias T-218 de 2012, T-951 de 2013, T-272 de 2014 y T-373 de 2014, se fijaron los requisitos específicos y los requisitos generales de procedencia excepcional de la acción de tutela contra sentencias de tutela:

Requisitos especificos: (i) la acción de tutela presentada no comporte identidad procesal con la sentencia de tutela cuestionada; (ii) se demuestre de manera clara y suficiente que la decisión adoptada en la sentencia de tutela cuestionada fue producto de una situación de fraude (fraus omnia corrumpit); (iii) no exista otro medio ordinario o extraordinario eficaz para resolver la situación cuestionada y, (iv) no es procedente cuando la acción de tutela se interponga en contra de sentencias proferidas por la Corte Constitucional.

Requisitos generales: (i) que la cuestión que se discuta resulte de evidente relevancia constitucional; (ii) que se hayan agotado todos los medios, ordinarios y extraordinarios, de defensa judicial al alcance de la persona afectada, salvo que se trate de evitar la consumación de un perjuicio iusfundamental irremediable; (iii) que se cumpla el requisito de la inmediatez; (iv) cuando se trate de una irregularidad procesal, debe quedar claro que la misma tiene un efecto decisivo o determinante en la sentencia que se impugna y que afecta los derechos fundamentales de la parte actora y, (v) que la parte actora identifique de manera razonable tanto los hechos que generaron la vulneración como los derechos vulnerados y que hubiere alegado tal vulneración en el proceso judicial siempre que esto hubiere sido posible.

El precedente constitucional fijado en la sentencia SU-627 de 2015 se puede calificar como estable y consolidado, o por lo menos con dicha pretensión, porque ha sido reiterado recientemente en las sentencias T-591 de 2016, T-427 
de 2017, T-633 de 2017, T-072 de 2018, T-093 de 2018 y T-322 de 2019. Sin embargo, la doctrina constitucional relacionada con la regla general de improcedencia de la acción de tutela contra sentencias de tutela no ha perdido vigencia y aplicabilidad en la jurisprudencia constitucional, debido a que la sentencia SU-627 de 2015, solo fijó una excepción a la regla general.

Esta procedencia excepcional de la acción de tutela contra sentencias de tutela permite afirmar que, en el actual Estado constitucional y democrático de derecho, el derecho válido además de ser creado por la autoridad dotada de competencia normativa para hacerlo, está íntimamente relacionado con el valor-principio de la justicia material, entendida como la salvaguarda y efectividad de los valores, principios y derechos fundamentales que conforman el núcleo esencial de la Constitución. Por esta razón, una sentencia que no garantice estos contenidos materiales no puede hacer tránsito a cosa juzgada material porque estos criterios normativos de especial protección constitucional no pueden sacrificarse en búsqueda de la seguridad jurídica.

El precedente constitucional fijado en la sentencia SU-627 de 2015, puede calificarse como una manifestación de la constitucionalización del derecho jurisprudencial en Colombia que se caracteriza por: (i) la reconfiguración del sistema de fuentes del derecho porque el precedente constitucional se convierte en una fuente formal y obligatoria del derecho que se encuentra en la misma escala jerárquica de la Constitución; (ii) la incorporación de nuevos métodos de interpretación, debido a que para resolverse un problema constitucional, además de cumplirse con el deber de interpretar y argumentar las disposiciones constitucionales, es necesario identificar el precedente constitucional vigente y aplicable para cada escenario constitucional y, (iii) la apertura a nuevas formas de litigio constitucional como lo son la acción de tutela contra providencias judiciales y la acción de tutela contra sentencias de tutela que tienen como fin constitucional incorporar en las sentencias los contenidos normativos que representan un mínimo de justicia material, esto es la salvaguarda de los valores y principios constitucionales y la efectividad de los derechos fundamentales de las partes involucradas en el proceso judicial.

\section{BiBLIOGRAFÍA CITADA}

Angarita Pinto, Alisson et al. (2017): “Transformación de la naturaleza de la acción de tutela: análisis en el ámbito del derecho a la salud en Colombia”, en Revista Verba Iuris (Vol. 12, No 38), pp. 91-110. 
Araújo Rentería, Jaime (2015): Filosofía o teoría del derecho constitucional. (Bogotá: Ibáñez).

Bernal Pulido, Carlos Libardo (2005): El Derecho de los derechos (Bogotá: Editorial Universidad Externado de Colombia).

Botero Marino, Catalina (2006): La acción de tutela en el ordenamiento jurídico colombiano (Bogotá: Escuela Judicial Rodrigo Lara Bonilla).

CAPELLA, Juan Ramón (1997): Fruta prohibida: una aproximación histórico teorética al estudio del derecho y del estado (Madrid: Editorial Trotta).

Carrera Silva, Liliana (2011): "La acción de tutela en Colombia", en Revista IUS (Vol. V, No 27), pp. 72-94.

Castaño Zuluaga, Luis Ociel (2010): Poder judicial, democracia y control de constitucionalidad (Bogotá: Editorial Leyer).

Chacón Mata, Alfonso (2015): "La cosa juzgada fraudulenta en la jurisprudencia de la Corte Interamericana de Derechos Humanos: implicaciones para el Estado de derecho contemporáneo", en Revista Prolegómenos (Vol. XVIII, No 35), pp. 169-188.

Chinchilla, Tulio (2010): ¿Qué son y cuáles son los derechos fundamentales? (Bogotá: Temis).

Correa Henao, Néstor Raúl (2009): Derecho procesal de la acción de tutela (Bogotá: Editorial Grupo Editorial Ibáñez).

De Отто, Ignacio (1987): Derecho Constitucional. Sistema de fuentes (Barcelona: Editorial Ariel).

Ferrajoli, Luigi (2003): "Pasado y futuro del Estado de Derecho", en CarboNELL, Miguel. Neoconstitucionalismo(s) (Madrid: Editorial Trotta), pp. 13-30.

Giacomette Ferrer, Ana (2017): "Selección y revisión de tutela por la Corte Constitucional: ¿Nuevo litigio constitucional?”, en Ferrer Mac-Gregor, Eduardo. Flores Pantoja, Rogelio. La Constitución y sus garantías. A 100 años de la Constitución de Queretano de 1917 (Queretano: Editorial Instituto de Estudios Constitucionales del Estado de Queretano), pp. 405-429.

GonZÁlez ManRIQue, Uriel et al. (2014): "Innovación jurisprudencial del derecho procesal constitucional colombiano: efectos de sentencias inter pares e inter comunis", en Revista Principia Iuris (No 21), pp. 169-193.

GUASTINI, Ricardo (2003): "La constitucionalización del ordenamiento jurídico: el caso italiano", en Carbonell, Miguel. Neoconstitucionalismo(s) (Madrid: Editorial Trotta), pp. 49-74. 
Kelsen, Hans (1995): ¿Quién debe ser el defensor de la Constitución? (Madrid: Editorial Tecnos).

(1993): "La garantía jurisdiccional de la Constitución (La Justicia Constitucional)", en Escritos sobre la democracia y el socialismo (Madrid: Editorial Debate), pp. 109-155.

López Medina, Diego Eduardo (2006): El derecho de los jueces, segunda edición (Bogotá: Editorial Legis).

Moreno Ortiz, Luis Javier et al. (2018): "Análisis jurisprudencial de la cosa juzgada constitucional”, en Revista Jurídicas (Vol. 15, No 1), pp. 9-27.

NisimbLAT, Nattan (2009): "La cosa juzgada en la jurisprudencia constitucional colombiana y el principio del estoppel en el derecho anglosajón”, en Revista Vniversitas (No 118), pp. 247-271.

Nogueira Alcalá, Humberto (2013): Derechos fundamentales y garantías constitucionales. Tomo 1. (Santiago: Editorial Librotecnia).

Pozzolo, Susanna (1998): "Neoconstitucionalismo y especificidad de la interpretación constitucional”, en Revista DOXA (Vol. II, No 21), pp. 339-353.

Restrepo Tamayo, John Fernando (2018): Estructura constitucional del estado colombiano, segunda edición (Medellín: Editorial Sello editorial Universidad de Medellín).

(2015): "Aproximación al pensamiento jurídico-político de Hans Kelsen”, en Revista Jurídicas (Vol. 12, No 1), pp. 43-58.

Uscanga Barradas, Abril; López Cárdenas, Carlos Mauricio (2011): "La protección de los derechos fundamentales frente a particulares: el amparo en México y la acción de tutela en Colombia”, en Revista de la Faculta de Derecho de México (Vol. 61, No 256), pp. 337-361.

Usquiano Castro, Milton Alexander (2017): La excepción de inconstitucionalidad en la Corte Constitucional colombiana (Medellín: Editorial Sello editorial Universidad de Medellín).

VILA CASADO, Iván. (2009): Fundamentos del derecho constitucional contemporáneo. (Bogotá: Legis).

Zagrebelsky, Gustavo. (1999): El derecho dúctil. Ley, derechos, justicia. (Madrid: Trotta).

\section{NORMAS JURÍDICAS CITADAS}

Acuerdo 002 de 2015. Por medio del cual se unifica y actualiza el Reglamento de la Corte Constitucional. Diario Oficial (Colombia), 1 de septiembre de 2015. 
Constitución Política de Colombia de 1991. Gaceta Constitucional (Colombia), 20 de julio de 1991.

Decreto No 2.067 de 1991. Por el cual se dicta el régimen procedimental de los juicios y actuaciones que deben surtirse ante la Corte Constitucional. Diario Oficial (Colombia), 4 de septiembre de 1991.

Decreto No 2.591 de 1991. Por el cual se reglamenta la acción de tutela consagrada en el artículo 86 de la Constitución Política. Diario Oficial (Colombia), 19 de noviembre de 1991.

Ley No 1.123 de 2007. Por el cual se establece el Código Disciplinario del Abogado. Diario Oficinal (Colombia), 22 de enero de 2007.

Ley No 1.564 de 2012. Por medio del cual se expide el Código General del Proceso y se dictan otras disposiciones. Diario Oficial (Colombia), 12 de julio de 2012.

\section{JURISPRUDENCIA CITADA ${ }^{87}$}

Corte Constitucional de Colombia. Auto 217 de 2006. M.P. Humberto Antonio Sierra Porto.

Corte Constitucional de Colombia. Auto 048 de 2013. M.P. Luis Ernesto Vargas Silva.

Corte Constitucional de Colombia. Auto 347 de 2016. M.P. Alberto Rojas Ríos.

Corte Constitucional de Colombia. Sentencia T-006 de 1992. M.P. Eduardo Cifuentes Muñoz.

Corte Constitucional de Colombia. Sentencia T-406 de 1992. M.P. Ciro Angarita Barón.

Corte Constitucional de Colombia. Sentencia C-543 de 1992. M.P. José Gregorio Hernández Galindo.

Corte Constitucional de Colombia. Sentencia C-054 de 1993. M.P. Alejandro Martínez Caballero.

Corte Constitucional de Colombia. Sentencia T-149 de 1995. M.P. Eduardo Cifuentes Muñoz.

${ }^{87}$ La jurisprudencia citada puede consultarse en la página web de la Corte Constitucional de Colombia: http://www.corteconstitucional.gov.co. 
Corte Constitucional de Colombia. Sentencia T-443 de 1995. M.P. Alejandro Martínez Caballero.

Corte Constitucional de Colombia. Sentencia C-037 de 1996. M.P. Vladimiro Naranjo Mesa.

Corte Constitucional de Colombia. Sentencia T-001 de 1997. M.P. José Gregorio Hernández Galindo.

Corte Constitucional de Colombia. Sentencia SU-047 de 1999. M.P. Carlos Gaviria Díaz y Alejandro Martínez Caballero.

Corte Constitucional de Colombia. Sentencia C-774 de 2001. M.P. Rodrigo Escobar Gil.

Corte Constitucional de Colombia. Sentencia SU-1219 de 2001. M.P. Manuel José Cepeda Espinosa.

Corte Constitucional de Colombia. Sentencia T-354 de 2002. M.P. Marco Gerardo Monroy Cabra.

Corte Constitucional de Colombia. Sentencia T-774 de 2004. M.P. Manuel José Cepeda Espinosa.

Corte Constitucional de Colombia. Sentencia C-590 de 2005. M.P. Jaime Córdoba Triviño.

Corte Constitucional de Colombia. Sentencia SU-713 de 2006. M.P. Rodrigo Escobar Gil.

Corte Constitucional de Colombia. Sentencia T-509 de 2006. M.P. Mauricio González Cuervo.

Corte Constitucional de Colombia. Sentencia T-282 de 2009. M.P. Gabriel Eduardo Mendoza Martelo.

Corte Constitucional de Colombia. Sentencia SU-026 de 2012. M.P. Humberto Antonio Sierra Porto.

Corte Constitucional de Colombia. Sentencia T-218 de 2012. M.P. Juan Carlos Henao Pérez.

Corte Constitucional de Colombia. Sentencia SU-198 de 2013. M.P. Luis Ernesto Vargas Silva.

Corte Constitucional de Colombia. Sentencia T-208 de 2013. M.P. Jorge Iván Palacio Palacio.

Corte Constitucional de Colombia. Sentencia T-951 de 2013. M.P. Luis Ernesto Vargas Silva. 
Corte Constitucional de Colombia. Sentencia T-373 de 2014. M.P. Luis Ernesto Vargas Silva.

Corte Constitucional de Colombia. Sentencia SU-055 de 2015. M.P. María Victoria Calle Correa.

Corte Constitucional de Colombia. Sentencia SU-297 de 2015. M.P. Luis Guillermo Guerrero Pérez.

Corte Constitucional de Colombia. Sentencia SU-627 de 2015. M.P. Mauricio González Cuervo.

Corte Constitucional de Colombia. Sentencia SU-659 de 2015. M.P. Alberto Rojas Ríos.

Corte Constitucional de Colombia. Sentencia T-307 de 2015. M.P. Luis Ernesto Vargas Silva.

Corte Constitucional de Colombia. Sentencia T-019 de 2016. M.P. Jorge Ignacio Pretelt Chaljub.

Corte Constitucional de Colombia. Sentencia T-031 de 2016. M.P. Luis Guillermo Guerrero Pérez.

Corte Constitucional de Colombia. Sentencia T-244 de 2016. M.P. Gloria Stella Ortiz Delgado.

Corte Constitucional de Colombia. Sentencia T-591 de 2016. M.P. Luis Guillermo Guerrero Pérez.

Corte Constitucional de Colombia. Sentencia T-208 de 2017. M.P. Antonio José Lizarazo Ocampo.

Corte Constitucional de Colombia. Sentencia T-406 de 2017. M.P. Iván Humberto Escrucería Mayolo.

Corte Constitucional de Colombia. Sentencia T-427 de 2017. M.P. Alejandro Linares Cantillo.

Corte Constitucional de Colombia. Sentencia T-633 de 2017. M.P. José Fernando Reyes Cuartas.

Corte Constitucional de Colombia. Sentencia T-072 de 2018. M.P. Carlos Bernal Pulido.

Corte Constitucional de Colombia. Sentencia T-093 de 2018. M.P. Luis Guillermo Guerrero Pérez.

Corte Constitucional de Colombia. Sentencia T-322 de 2019. M.P. José Fernando Reyes Cuartas. 
Corte Constitucional de Colombia. Sentencia C-100 de 2019. M.P. Alberto Rojas Ríos.

Corte Constitucional de Colombia. Sentencia SU-037 de 2019. M.P. Luis Guillermo Guerrero Pérez. 